\title{
Dos Medicamentos aOs Índios “GenéRicos": OS CAMPOS DAS POLÍTICAS INDIGENISTA E DE SAÚDE PARA os povos INdígenas, No Brasil, FRENTE ao CENSO Demográfico de 2000
}

FROM THE "GENERIC" MEDICINE TO THE "GENERIC" INDIANS:

THE FIELDS OF INDIGENIST AND HEALTH POLICIES TO INDIAN PEOPLES, IN BRAZIL, CONSIDERING THE 2000 DEMOGRAPHIC CENSUS

István van Deursen Varga $^{(*)}$

\section{RESUMO}

O Censo Demográfico de 2000, utilizando-se da auto-identificação para o preenchimento do quesito "cor ou raça", registrou 734.131 índios no Brasil, o que representa um aumento de mais de $100 \%$ em relação a todos os censos e estimativas anteriores, tanto de instituições de governo, quanto de organizações não-governamentais, sobre a população indígena no Brasil (muito mais acentuada em certos estados, como São Paulo, que registrou um aumento de $2.939,28 \%$, passando de uma população anteriormente estimada em cerca de 3.000 para a de 63.789 índios). Tanto as instituições governamentais quanto as não-governamentais vêm pautando sua ação indigenista em torno do paradigma dos indios oficialmente "aldeados" (tutelados por Postos Indígenas da Fundação Nacional do Índio, a Funai) e vivendo na floresta. Este é uma das principais explicações (juntamente com uma análise dos efeitos das políticas coloniais assimilacionistas aqui praticadas, à diferença das políticas de caráter mais segregacionista, aplicadas nos países de colonização espanhola, por exemplo) para a população indígena desproporcionalmente pequena em nosso país, frente às de outros países latino-americanos, bem menores que o Brasil. Estes dados

(*) Professor Adjunto do Departamento de Sociologia e Antropologia, e do Mestrado em Saúde e Ambiente da Universidade Federal do Maranhão; coordenador do I Fórum Nacional de Saúde Indígena, e da Comissão Organizadora da II Conferência Nacional de Saúde para os Povos Indígenas. E-mail: ivarga@uol.com.br - Recebido em 10-03-2003. Aprovado em 05-05-2003. 
apontam para a necessidade da adoção de outros referenciais teóricos e metodológicos no campo da política de saúde para os povos indígenas, e mesmo no da política indigenista no país.

\section{Descritores}

Política Indigenista; Política de Saúde; SUS(BR); Grupos Minoritários; Garantia de Acesso a Serviços de Saúde; Saúde Pública.

\section{ABSTRACT}

The 2000 demographic census, using the self-identification as a method to fill in the item "color or race", registered 734.131 Indians in Brazil. This represents a growth of more than $100 \%$ in relation to previous censuses and estimates carried out by either governmental institutions or non-governmental organizations concerning the Indian population in Brazil. The numbers also show that this growth was considerably higher in certain states such as São Paulo, which registered an increase of $2.939 .28 \%$, moving from a formerly estimated population of 3000 Indians to 63.789 Indians. Both governmental institutions and NGOs have been targeting their actions based on the paradigm of the Indians oficially "aldeados" (which are officially submitted to the guardianship regiment of the Postos Indigenas of the Fundação Nacional do Indio) and living in the forest. This is one of the main explanations, along with the analysis of the effects of the assimilative aspect of the colonial policies implemented here in contrast to the more segregationist approach of the policies applied to the countries colonized by Spain, to the disproportionately small Indian population in our country compared to other Latin-American countries, whose territories are much smaller than Brazil's. These data indicate the necessity of the adoption of other theoretical and methodological references in the Indian and health policies for the Indian peoples in Brazil.

\section{Key-words}

Indian Policies; Health Policies; Health System (Brazil); Minorities; Health Services Accessibility; Public Health.

\section{INTRODUÇÃO}

No Brasil, instituições governamentais e não-governamentais têm, de modo geral, pautado sua ação indigenista sobre o paradigma dos índios "aldeados" e vivendo na floresta. Os resultados do Censo Demográfico de 2000 apontam para a necessidade da adoção de outros referenciais teóricos e metodológicos no campo da política de saúde para os povos indígenas, e mesmo no da política indigenista no país. 


\section{"INDIGENISMO", "SANITARISMO INDIGENISTA" E O PROCESSO DE CONSTRUÇÃO DO SISTEMA ÚNICO DE SAÚDE (SUS)}

O processo de construção do SUS tem apresentado problemas e características bastante heterogêneas, entre os diversos segmentos da população. A nosso ver(1), além da evidente afronta aos interesses dos vários setores contrários aos princípios do SUS, seu processo de implantação tem se mostrado problemático, em grande medida, por seu caráter eminentemente dialético: implica não apenas numa transformação estrutural das instituições envolvidas e de suas políticas, mas de suas "práticas" sociais ${ }^{(2)}$.

Como procuramos demonstrar anteriormente ${ }^{(3)}$, no que concerne ao contexto Maranhão, por exemplo, as práticas das instituições e entidades voltadas à atenção à saúde dos povos indígenas têm sido, de modo geral, refratárias às práticas e instâncias participativas e de controle social do SUS, específicas da política de saúde para os povos indígenas. Um dos argumentos centrais de nossa tese é de que as instâncias e as práticas formalizadas pela I e II Conferências Nacionais de Saúde para os Povos Indígenas são incompatíveis com as regras dos "jogos"(4) políticos já configurados nos campos da política indigenista e de saúde.

Apesar de seus respectivos discursos e posições políticas oficiais (reconhecendo e assumindo o compromisso de implementar essas instâncias e práticas), essas instituições e entidades, e seus agentes, galvanizados pelos jogos de disputas políticas estabelecidos em seus respectivos campos de ação, e neles tendo já consolidado posições e nichos específicos, passam a empenhar-se na preservação da hegemonia conquistada nestes espaços, solapando a emergência de novos interlocutores (em torno deles configurando, assim, o que chamaremos aqui de subcampos). Este processo, por sua vez, tende a reafirmar uma certa "cultura" geral partilhada, paradoxalmente, por instituições, entidades e agentes de posições opostas em seus respectivos campos de ação: a da participação e do interesse na manutenção do mesmo jogo político já estabelecido.

Entretanto, nas trajetórias de todos esses campos e subcampos sociais, e de seus respectivos e diversos espaços e posições, surgem fissuras (que em Varga 2002 denominamos de "trincheiras"(5)), a partir de

(1) Cf. VARGA, István van Deursen. Pelas fronteiras e trincheiras do indigenismo e do sanitarismo: a atenção às DST em comunidades indígenas, no contexto das políticas e práticas indigenistas e de saúde, na Pré-Amazónia. 2002. Tese (Doutorado) — Faculdade de Saúde Pública, Universidade de São Paulo, 2002.

(2) BOURDIEU, Pierre. Razões práticas: sobre a teoria da ação. Trad. Mariza Corrêa. Campinas: Papirus, 1996.

(3) VARGA, István van Deursen. op. cit.

(4) BOURDIEU, Pierre. op. cit.

(5) VARGA, István van Deursen. op. cit. 
tensões e conflitos inter e intra-institucionais que, embora geralmente absorvidos e abafados internamente pelos instrumentos de repressão e/ou de cooptação de cada instituição, culminam em rupturas mais sonoras, que chegam a vir a público e, na perspectiva de princípios "éticos" "superiores", por vezes expõem as contradições entre os discursos e práticas dessas instituições e entidades, denunciando os jogos políticos estabelecidos e buscando "subvertê-los":

"As estratégias dos agentes e das instituições que estão envolvidos nas lutas... ...isto é, suas tomadas de posição... ...dependem da posição que eles ocupam na estrutura do campo, isto é, na distribuição do capital simbólico específico, institucionalizado ou não (reconhecimento interno ou notoriedade externa) e que, através da mediação das disposições constitutivas de seus habitus (relativamente autônomos em relação à posição), inclina-os seja a conservar seja a transformar a estrutura dessa distribuição, logo, a perpetuar as regras do jogo ou a subvertê-las."(6) (destaques do autor)

Em Varga (2002) buscamos estabelecer conexões e identidades entre as crises e rupturas internas das instituições e entidades envolvidas em ações de atenção à saúde de povos indígenas no Maranhão, e os princípios e diretrizes definidos pelas Conferências Nacionais de Saúde para os Povos Indígenas.

Procuramos demonstrar que, mesmo quando essas crises e rupturas envolveram agentes que não participaram dessas Conferências nem tiveram contato anterior com seus documentos finais, seus protestos e denúncias são identificáveis a vários dos princípios por elas definidos - 0 que nos parece reforçar sua legitimidade, e as perspectivas políticas para a transformação, não apenas das diretrizes políticas e das práticas de cada uma dessas instituições e entidades, como das próprias regras do jogo em vigor, ao menos nesse campo do "indigenismo sanitarista".

\section{ÍNDIOS, CABOCLOS, SERTANEJOS, CAIPIRAS, CAIÇARAS}

No Brasil, como apontam Ribeiro(7) e vários outros autores, à parte as guerras de extermínio praticadas contra muitos povos indígenas, a colonização portuguesa pautou-se por uma política marcadamente assimilacionista que, aparentemente suspendendo barreiras sociais e culturais, resultou numa intensa miscigenação entre europeus, indígenas e africanos. Nos países de colonização espanhola, ao contrário, a segregação racial

(6) BOURDIEU, Pierre. op. cit. p. 63-64.

(7) RIBEIRO, Darcy. O povo brasileiro: a formação e o sentido do Brasil. São Paulo: Companhia das Letras, 1997. 
resultou na formação de segmentos étnicos bem mais delimitados, numerosos e populosos que os do Brasil, e na preservação, até nossos dias, de seus respectivos idiomas, culturas e identidades específicas, inclusive como forma de resistência à colonização européia.

Este processo de miscigenação, estimulado e dirigido pelo projeto colonial português, resultou, por sua vez, na configuração de outras sociabilidades e culturas - geralmente caracterizadas como "rurais" - bastante distintas entre si, herdeiras das culturas indígenas (como a cultura "cabocla", a "sertaneja", a "caipira" e a "caiçara", nas categorizações adotadas por autores como Cândido e Ribeiro) $)^{(8)}$.

A construção da identidade nacional, na consolidação da independência do Brasil, foi fortemente influenciada, no entanto, pelo positivismo e pelo evolucionismo, que reforçaram preconceitos racistas já herdados do período colonial (aos quais, nesse contexto, várias personalidades brasileiras ilustres, como o médico e antropólogo maranhense Raimundo Nina Rodrigues, emprestaram uma aura científica e de modernidade), o que contribuiu significativamente para o desaparecimento de vários desses idiomas e culturas.

Esses preconceitos (profundamente arraigados, portanto, na própria identidade brasileira), de modo sub-reptício, quando não explicitamente, desvalorizam as identidades $e$ as ascendências indígenas e africanas, consideradas "inferiores" ou "atrasadas" e, portanto, desonrosas, resultando em sua (ainda hoje freqüente) negação ou escamoteamento entre as pessoas.

Pelos motivos expostos, boa parte da população brasileira, com ascendência e características culturais (e mesmo fenotípicas) marcadamente indígenas, sequer reconhece este fato, e termina sendo computada, pelos censos, contagens populacionais e pesquisas do Instituto Brasileiro de Geografia e Estatística (IBGE), nas categorias de "cor" ou "raça" "parda", "não declarada" ou mesmo "branca": é certamente o caso dos caboclos e sertanejos do Maranhão e da Amazônia, e dos caipiras e caiçaras de São Paulo e do Sudeste, por exemplo.

A Fundação Nacional do Índio (Funai) vem sendo a instituição responsável pela coleta e divulgação dos dados oficiais sobre a população indígena no Brasil. Para as contagens da Funai, consideram-se "índios" apenas aqueles que habitam "aldeias indígenas" reconhecidas e/ou sob jurisdição de seus Postos Indígenas (PIs).

Em São Paulo, por exemplo, várias comunidades Guarani, que têm insistido em não submeter-se à tutela de PIs da Funai, sequer são computadas como comunidades indígenas por esta instituição( ${ }^{(9)}$, caso dos muni-

(8) CÂNDIDO, Antonio. Os parceiros do rio Bonito: estudo sobre o caipira paulista e a transformação dos seus meios de vida. São Paulo: Livraria Duas Cidades, 1977; RIBEIRO, Darcy. op. cit. (9) LADERIA, Maria Inês. As demarcações Guarani, a caminho da terra sem mal. In: Povos indigenas do Brasil 1996/2000. São Paulo: Instituto Socioambiental, 2001. p. 783. 
cípios de Cananéia, Iguape, Miracatu, Pariquera-Açu, Sete Barras e Registro(10), no Vale do Ribeira - região que concentra a quase-totalidade das Terras Indígenas "sem providências administrativas" do estado.

\section{ÍNDIOS “GENÉRICOS”?}

Os resultados parciais do Censo Demográfico realizado entre $1^{9}$ de agosto a 30 de novembro de 2000 (que incluiu a categoria "indígena" no item "cor" de seus questionários, a ser preenchido conforme auto-identificação dos indivíduos recenseados(11)), divulgados pelo IBGE em maio de $2002^{(12)}$, parecem apontar para uma inflexão histórica da tendência de desvalorização das identidades negra e indígena (anteriormente comentada), já indicando, em relação ao censo de 1991, uma diminuição da porcentagem dos que se declararam "pardos" (de 42,6\%, para 39,1\%), e um aumento dos que se declararam "pretos" (de 5,0\% para 6,2\%) e "indios" (de 0,2\% para $0,4 \%$, num total de 734.131 indivíduos), extrapolando, no caso dos índios, todas as contagens e estimativas até então produzidas, por instituições e entidades indigenistas, governamentais e não-governamentais (duplicando, por exemplo, a estimativa do Instituto Socioambiental, de $\left.2001^{(13)}\right)$.

Segundo esses dados preliminares já divulgados pelo IBGE, a população indígena no estado de São Paulo, por exemplo, passa a ser de 63.789 indivíduos: a terceira maior do país, superada apenas pelas do estado do Amazonas (de 113.391 indivíduos) e da Bahia (de 64.240 indivíduos), compondo $8,689 \%$ do total da população indígena no Brasil.

Representantes do Instituto Socioambiental (ISA) e alguns antropólogos apressaram-se em comentar e contestar estes dados, que vêm acarretando visíveis constrangimentos, tanto às instituições do Estado quanto às organizações não-governamentais (ONGs) executoras das políticas públicas voltadas aos povos indígenas no país:

"As informações que o ISA vem divulgando permanentemente sobre populações indígenas baseiam-se em um conjunto de recenseamen-

(10) Cf. GOMES, Selma Aparecida. Localização das Terras Indígenas no Estado de São Paulo. São Paulo: Comissão Pró-Índio, 2002. Mimeo. Mapa. A informação sobre o agrupamento Guarani em Registro foi por nós colhida, em dezembro de 2002, de Algemiro Guarani, professor da Terra Indígena Guarani do Bracuí, no Rio de Janeiro.

(11) O primeiro Censo Demográfico do IBGE a inclui-la foi o de 1991, que computou um total de 294.131 indios.

(12) Cf. INSTITUTO BRASILEIRO DE GEOGRAFIA E ESTATístiCA. 2002. Censo Demográfico 2000 - Resultados da Amostra - Tabela 2.1.1 - população residente, por cor ou raça, segundo as Grandes Regiões e as Unidades da Federação, 2002. Disponivel em: <http://www.ibge.gov.br/ home/estatistica/populacao/cens02000/primeiros_resultados_amostra/grandes_regioes/pdf/ tabela_2_1_1.pdf>.

(13) Cf. INSTITUTO SOCIOAMBIENTAL. Povos Indigenas no Brasil 1996/2000. São Paulo: Instituto Socioambiental, 2001. 
tos completos feitos em campo por diferentes fontes e referem-se apenas a povos indígenas específicos, que se reconhecem e são reconhecidos como tais. Freqüentemente, a parte da população que se encontra fora das aldeias e das terras indígenas, vivendo em cidades, sobre as quais há estimativas vagas, costuma escapar da contagem desses censos étnicos. Porém, mesmo as mais otimistas, nunca passaram de 550 mil. Portanto, o patamar de 700 mil divulgado agora pelo IBGE é uma novidade que merece explicações apropriadas, o que somente será possível com análises dos dados decupados por localização, por exemplo."(14)

A nosso ver, o desenrolar desta discussão terá grande impacto sobre o campo indigenista no Brasil, colocando em evidência não apenas os contingentes indígenas até então "invisíveis" — os índios ditos "mestiços", "desaldeados", "urbanizados" - e, mais recentemente, ditos "genéricos" (cf. declarações de interlocutoras do ISA, abaixo - e as etnias indígenas ditas "reemergentes": todos reconhecendo-se e reivindicando-se, de algum modo, cidadãos brasileiros indígenas), cuja dimensão e evidência, em nossa opinião, só tende a crescer, e imporá uma rediscussão sobre a própria categoria "índio" e os critérios de "indianidade", sobre suas aplicações e, conseqüentemente, sobre as políticas indigenistas do governo e das ONGs, assim como sobre seus respectivos estatutos, campos de ação e responsabilidades sociais ${ }^{(15)}$.

Já nos parecem especialmente emblemáticas, nesse sentido, as conotações de algumas das afirmações iniciais dessas mesmas interlocutoras do ISA:

“...não dá para saber se, de fato, os que se auto-classificaram como 'índios' no censo 2000 reconhecem vinculação específica a uma etnia ou são apenas 'índios genéricos'”'(16) (grifo nosso, aspas do original).

- Porque a referência aos ditos "índios genéricos" aparece aqui precedida do qualificativo "apenas"? Acaso indicaria que estes seriam, de algum modo, "menos índios" que os que "reconhecem vinculação específica a uma etnia"? Ou que "apenas" os critérios lingüísticos - e não os sociais (como a auto-identificação, no caso) - seriam legítimos para determinar essas identidades?

(14) AZEVEDO, Marta; RICARDO, Fany. Censo do IBGE revela contingente "indígena" pouco conhecido. Notícias Socioambientais, 13-5-2002. Disponivel em: <http://www.socioambiental.org/ website/noticias/noticia.asp?File=Indios $12002-05-10-11-05 . \mathrm{html}$.

(15) VARGA, István van Deursen. Dos medicamentos aos indios "genéricos": sobre os problemas e desafios legados, pelo governo Fernando Henrique Cardoso, aos campos das políticas indigenista e de saúde para os povos indígenas no Brasil (documento encaminhado ao governo Lula, como subsídio para aprofundar as discussões acerca da proposta resultante do seminário "Bases para uma nova política indigenista - 2", realizado pelo LACED/Museu Nacional, APOINME e COIAB). São Paulo, 2003. Mimeo.

(16) AZEVEDO, Marta; RICARDO, Fany. op. cit. 
As declarações dessas autoras parecem sugerir que os verdadeiros(?) índios, os indivíduos de "povos indígenas específicos", para fazerem jus a essa condição, devem não apenas identificar-se, mas também ser "reconhecidos como tais". As autoras não explicitam, entretanto, a qual instituição ou ator(es) social(is) caberia "reconhecê-los como tais": de qualquer modo, seu discurso assemelha-se, nesse aspecto, ao da tutela(17), apontando para uma perspectiva política oposta à da "autodeterminação", que pautou as propostas, reivindicações e conquistas do movimento indígena brasileiro, ao longo das décadas de 1970, 1980 e 1990.

A confirmar-se estes sentidos que inferimos das declarações acima, parece-nos que também esboça-se aqui a reedição de posições do já clássico debate sobre o processo de "aculturação" - de grupos indígenas que passam a freqüentar ou fixar residência em centros urbanos - há muito questionado (e que supúnhamos superado) no campo da etnologia indígena brasileira:

“...haveríamos de entender - como efetivamente acabamos por concluir ao fim de nosso estudo - que essa mobilidade, incluindo nos espaços físico e social, respectivamente com a migração e com a acomodação num sistema de classes de tipo urbano, implicava também a permanência da primitiva identidade étnica ou, em outras palavras, a manutenção da condição de membro do grupo tribal. Isso significa integração sem assimilação, tese essa levantada no mencionado trabalho(18) e agora demonstrada, acreditamos, através da análise dos mecanismos sociais emergentes das condições de contato interétnico"(19).

De qualquer modo, todos os interlocutores que se têm pronunciado sobre estes dados são unânimes em neles reconhecer, de um modo ou de outro, a manifestação de um processo de revalorização dessas identidades raciais e/ou de sua ascendência:

"O Brasil tem discutido muito a questão do preconceito racial, a política de cotas, e isso se reflete no aumento das declarações de cor preta. A nossa hipótese é que parte desses pardos passou a se assumir como preta ou indígena" (declaração de Nilza Oliveira Martins Pereira, demógrafa e estatística do IBGE)(20).

(17) Compare-se com o texto do Estatuto do Índio, forjado durante a ditadura militar: "Índio ou Silvícola - É todo indivíduo de origem e ascendência pré-colombiana que se identifica e é identificado como pertencente a um grupo étnico cujas características culturais o distingem da sociedade nacional;" (Estatuto do Índio, 1973, artigo $3^{2}$ ).

(18) OLIVEIRA, Roberto Cardoso de. O processo de assimilação dos Terena. Rio de Janeiro: Museu Nacional, Universidade do Brasil, Rio de Janeiro, 1960. (Série Livros I.)

(19) Id. Urbanização e tribalismo: a integração dos índios Terena numa sociedade de classes. Rio de Janeiro: Zahar, 1968. p. 11.

(20) Folha de S.Paulo, 2002. p. A3. 
"Certamente a explicação para a duplicação da população que se considera indigena nos dez anos entre os censos é uma composição de fatores que inclui: (a) o crescimento demográfico real da maior parte das 218 etnias sobre as quais há informações confiáveis mesmo através de outras fontes que não o IBGE; (b) o fato de que populações indígenas urbanas que normalmente escapam aos censos tradicionalmente feitos para povos indígenas específicos se declararam como tais aos recenseadores do IBGE; (c) o aparecimento de um contingente de pessoas que se classificaram genericamente como 'índios'. (....) Afinal, estamos vivendo um tempo de valorização étnica, que teve início com o crescimento do movimento indígena pós Constituição de 1988."(21)

O questionamento, por parte dessas autoras, dos dados do Censo Demográfico de 2000 não remete, no entanto, ao campo antropológico (como o faria uma discussão sobre os conceitos de identidade, propriamente ditos), mas ao campo das políticas públicas, parecendo expressar sobretudo preocupações acerca das responsabilidades institucionais em face de direitos conquistados (específicos da condição "indigena") de assistência por parte do Estado - e por parte das ONGs que se atribuíram o papel de executoras de suas políticas (como no campo da saúde, com a atual política de terceirização de serviços, da Fundação Nacional de Saúde):

"Esse ambiente pode reforçar, por vários caminhos, a 'síndrome da avó indígena' o que, de resto, seria tão legítima quanto o movimento de descendentes italianos de quarta geração que buscam obter passaporte europeu na esperança de facilidades para uma vida melhor."(22)

Está claro que as autoras optaram aqui por uma analogia a uma situação de reivindicação de direitos sociais - o "movimento de descendentes italianos de quarta geração" - cuja legitimidade vem sendo questionada e contestada pelo próprio governo italiano.

Poderiamos, no entanto, aludir a outras situações também análogas que, em nossos dias, já não têm sido motivo de tantos questionamentos no mundo ocidental, como a dos descendentes de israelitas, de às vezes dezenas de gerações anteriores, que mantêm sua identidade étnica, religiosa (e mesmo nacional) judaica simultaneamente a outra(s) identidade(s) - o que, segundo vários autores ${ }^{(23)}$, é fenômeno característico da chamada "pós-modernidade". Seguindo o argumento de Azevedo

(21) AZEVEDO, Marta; RICARDO, Fany. op. cit.

(22) Id. Ibid.

(23) Cf. HALL, Stuart. A identidade cultural na pós-modernidade. Trad. Tomaz Tadeu da Silva e Guacira Lopes Louro. Rio de Janeiro: DP\&A Ed., 2000; HARDT, Michael; NEGRI, Antonio. Império.

Trad. Berilo Vargas. Rio de Janeiro: Record, 2001. 
e Ricardo, seriam estes também "apenas judeus genéricos", e sua atitude também "tão legítima" (leia-se tão questionável...) quanto "o movimento de descendentes italianos de quarta geração que buscam obter passaporte europeu na esperança de facilidades para uma vida melhor" e o "síndrome da avó indígena'"?...

\section{CONCLUSÃO}

\section{SUS, DSEIS, SAÚDE E “INDIANIDADE”: DESAFIOS PARA O GOVERNO LULA}

Apesar da política de divulgação tardia e seletiva dos dados de saúde e relatórios dos DSEls da Funasa do período 1999-2002, os dados que de algum modo já romperam essa barreira, e aos quais já pudemos ter acesso (como os de prevalência das DST nos DSEls) ${ }^{(24)}$, confirmam o que já prevíamos: os DSEls mais problemáticos e de pior desempenho, nesse período, foram os do Nordeste, Sudeste e Sul.

Discordamos, portanto, da correlação estabelecida pelas interlocutoras do ISA entre o significativo índice de auto-identificados como "indígenas" no Censo de 2000, e suas expectativas quanto à implantação dos DSEls da FUNASA:

"Além do mais, desde 1999, com a implantação de 34 Distritos Sanitários Especiais Indígenas em todo o país, pode-se supor que uma onda de expectativa de acesso diferenciado a serviços médicos possa ter animado muita gente a declarar-se 'indio'."(25)

Os dados parciais de população indígena do Censo de 2000 que apresentam maior aumento e discrepância em relação aos dados anteriores da Funai, da Funasa e do ISA são, justamente, os dos estados do Sudeste (entre os quais se destaca o do estado de São Paulo, que apresentou a maior discrepância entre os de toda a federação, com um aumento de cerca de $2.939,28 \%$ em relação aos dados do ISA) e do Nordeste (entre os quais se destacam os da Bahia, com um aumento de cerca de 585,32\% e os do Maranhão, com um aumento de $\left.287,37 \%^{(26)}\right)$, onde os DSEls da

(24) VARGA, István van Deursen. Dos medicamentos aos índios "genéricos": sobre os problemas e desafios legados, pelo governo Fernando Henrique Cardoso, aos campos das políticas indigenista e de saúde para os povos indígenas no Brasil (documento encaminhado ao governo Lula, como subsídio para aprofundar as discussões acerca da proposta resultante do seminário "Bases para uma nova política indigenista - 2", realizado pelo LACED/Museu Nacional, APOINME e COIAB). São Paulo, 2003. Mimeo.

(25) AZEVEDO, Marta; RICARDO, Fany. op. cit.

(26) Entre os estados do Nordeste chamam também atenção os dados do Piauí e os do Rio Grande do Norte: segundo a FUNASA (2000), ambos não apresentavam população indígena; segundo o 
Funasa têm tido pior desempenho, e tornam bem menos plausível a idéia de que seu desempenho "possa ter animado muita gente a declarar-se 'índio", como sugerem Azevedo e Ricardo(27).

A perspectiva desse grande salto dos dados de população indígena de São Paulo, por exemplo, já se manifestava na Pesquisa Nacional por Amostra de Domicílos (PNAD) de 1998: nada menos que 33.829 pessoas já se identificavam, à época, como de "cor ou raça" "indígena", só na Região Metropolitana de São Paulo(28) — antes, portanto, da implantação dos DSEls da Funasa - o que refuta os argumentos acima, destas autoras.

Concordamos com estas interlocutoras do ISA, no entanto, no que se refere à predominância, nesses saltos numéricos, de contingentes de pessoas indígenas habitando domicílios urbanos (pudemos verificar processo de urbanização também entre os Guajajara da Pré-Amazônia, no Maranhão, por exemplo(29)), mas esse contingente de índios "urbanos" é justamente daqueles que não têm sido reconhecidos pela Funai e pela Funasa (ou que apenas mais recentemente começam a ser reconhecidos e acessados, como vem ocorrendo em São Paulo) - nem, ao que parece, pelo ISA - como "índios" que fazem jus aos direitos e serviços específicos do Estado, previstos na legislação em vigor.

Segundo informações colhidas junto a várias lideranças indígenas da Amazônia e do Nordeste, o Diretor do Desai/Funasa, no período 1998-2003, teria tentado desencorajá-las a reivindicar o direito de atenção diferenciada à saúde para essas comunidades "urbanizadas", argumentando que isso acarretaria a redução dos recursos da Funasa disponiveis para o atendimento dos índios "aldeados".

Apesar das dificuldades (e resistências) da parte da Funai e da Funasa em comprometer-se com o enfrentamento dos problemas e necessidades dessas comunidades, o movimento indígena já se manifestou clara e especificamente acerca desta questão, como atesta o Relatório Final da III Conferência Nacional de Saúde Indígena (Luziânia/GO, 14-18 de maio de 2001) que, entre as "atribuições/responsabilidades do órgão gestor da saúde indígena/Ministério da Saúde", elenca a de...

"incluir os povos indígenas ainda não reconhecidos oficialmente e os índios que residem fora das terras indígenas, no planejamento das

Censo de 2000, no Piaui 2.106 e no Rio Grande do Norte 598 pessoas identificaram-se como indígenas.

(27) AZEVEDO, Marta; RICARDO, Fany. op. cit.

(28) INSTITUTO BRASILEIRO DE GEOGRAFIA E ESTATíSTICA. Pesquisa Nacional por Amostra de Domicílios. Rio de Janeiro: IBGE, 1998.

(29) Cf. VARGA, István van Deursen; GARCEZ, Jeovany, 1998. Censo da população indígena residente na Vila Santa Rosa, município de Amarante do Maranhão. Imperatriz: Projeto de atenção às DST para comunidades indígenas do Maranhão - UFMAVCCS/MSA, Funai/AER-Imperatriz (mimeo). 
atividades dos distritos, conforme especificidades locais e com a participação dos conselhos distritais"(30).

Os receios (como os acima referidos, do ex-Diretor do Desai da Funasa) acerca da "governabilidade" orçamentária de uma política nacional de saúde específica para os povos indígenas, diante dessa deliberação da III Conferência e, mais recentemente, dos dados do Censo Demográfico de 2000 (que, como vimos, atestam a duplicação e apontam para um acelerado processo de expansão do contingente indígena da população brasileira), parecem-nos decorrer de uma concepção excessivamente centralizada (atualmente, na Funasa, outrora na Funai) da gestão e da execução dessa política, que não investe em sua capilarização para todas as instâncias, niveis de atenção e serviços do SUS.

Mais que "ameaçar" o tamanho da fatia do orçamento federal para os índios não "aldeados", esses dados apontam para a necessidade de uma mudança nessa política, a começar pela adoção de um paradigma mais abrangente e inclusivo sobre a condição indígena (a "indianidade"), e mais compatível, inclusive, com discussões há décadas em andamento no campo das ciências sociais, como vimos, sobre a própria questão das identidades culturais e étnicas.

Estes dados também indicam, finalmente, a necessidade da adoção de estratégias para a disseminação dessa política em todos os níveis de gestão do SUS, e de metodologias de trabalho mais efetivamente participantes, que resultem numa profunda transformação das práticas "sanitárias" e "indigenistas"(31) em uso "na ponta", em todos os níveis de sua execução, inclusive nos serviços de saúde que atendem os índios ditos "urbanizados".

Propor a difusão dessa responsabilidade e da política de saúde para os povos indígenas para todos os níveis do SUS, segundo seus próprios princípios e diretrizes, não significa "municipalizar" a saúde indígena (que foi, na prática, a política adotada pelo Desai no Maranhão e no Nordeste, no período 1999-2002, por exemplo), nem abdicar da responsabilidade prioritária da esfera federal sobre a gestão da política nacional de saúde (o "comando único", que também é um dos princípios e diretrizes do SUS), sobretudo no que se refere à saúde dos povos indígenas (que foram lesados pelo Estado nacional em formação, e cuja saúde, portanto, é prioritariamente de sua responsabilidade).

No caso da política de saúde para os povos indígenas, a nosso ver, cabe à esfera federal, sobretudo - para além e acima da execução direta (ou terceirizada) das ações de saúde sob sua responsabilidade - , reconhecer, fazer respeitar, cumprir e fazer cumprir essa política, definida nos

(30) III CONFERÊNCIA Nacional de Saúde Indígena. Relatório Final. Brasília: Funasa/Desai, 2001. p. 4. Mimeo.

(31) Id. Ibid. 
principios e diretrizes estabelecidos pelas Conferências Nacionais, èm todos os niveis de gestão e execução do SUS.

\section{REFERÊNCIAS BIBLIOGRÁFICAS}

AZEVEDO, Marta; RICARDO, Fany. Censo do IBGE revela contingente "indígena" pouco conhecido. Notícias Socioambientais, 13.5.2002. Disponível em: <http:// www.socioambiental.org/website/noticias/noticia.asp?File=Indios $12002-05-10$ 11-05.html>.

BOURDIEU, Pierre. Razões práticas: sobre a teoria da ação. Trad. Mariza Corrêa. Campinas: Papirus, 1996.

CÂNDIDO, Antonio. Os parceiros do rio Bonito: estudo sobre o caipira paulista e a transformação dos seus meios de vida. São Paulo: Livraria Duas Cidades, 1977.

I CONFERÊNCIA Nacional de Proteção à Saúde do Índio. Relatório Final. Brasília: Ministério da Saúde, 1986.

II CONFERÊNCIA Nacional de Saúde para os Povos Indígenas. Relatório Final. São Paulo: SES-SP/CADAIS, 1993. Mimeo.

III CONFERÊNCIA Nacional de Saúde Indígena. Relatório Final. Brasília: Funasa/Desai, 2001. Mimeo.

ESTATUTO DO ÍNDIO. Lei n. 6.001 - de 19 de dezembro de 1973. Brasília: Fundação Nacional do Índio. Disponivel em: <http://www.funai.gov.br/ funai.htm>.

GOMES, Selma Aparecida. Localização das Terras Indígenas no Estado de São Paulo. São Paulo: Comissão Pró-Índio, 2002. Mimeo. Mapa.

HALL, Stuart. A identidade cultural na pós-modernidade. Trad. Tomaz Tadeu da Silva e Guacira Lopes Louro. Rio de Janeiro: DP\&A Ed., 2000.

HARDT, Michael; NEGRI, Antonio. Império. Trad. Berilo Vargas. Rio de Janeiro: Record, 2001.

INSTITUTO BRASILEIRO DE GEOGRAFIA E ESTATísTICA. Censo Demográfico 2002 - Resultados da Amostra - Tabela 2.1.1 - população residente, por cor ou raça, segundo as Grandes Regiões e as Unidades da Federação, 2002. Disponivel em: <http://www.ibge.gov.br/home/estatistica/populacao/censo2000/primeiros_resultados_amostra/grandes_regioes/pdf/ tabela_2_1_1.pdf>.

1998.

. Pesquisa Nacional por Amostra de Domicílios. Rio de Janeiro: IBGE, . Síntese dos indicadores sociais. Rio de Janeiro: IBGE, 1998. 
INSTITUTO SOCIOAMBIENTAL. Povos Indígenas no Brasil 1996/2000. São Paulo: Instituto Socioambiental, 2001.

LADERIA, Maria Inês. As demarcações Guarani, a caminho da terra sem mal. In: Povos indígenas do Brasil 1996/2000. São Paulo: Instituto Socioambiental, 2001. p. 782-785.

OLIVEIRA, Roberto Cardoso de. O processo de assimilação dos Terena. Rio de Janeiro: Museu Nacional, Universidade do Brasil, Rio de Janeiro, 1960. (Série Livros I.)

. Urbanização e tribalismo: a integração dos índios Terena numa sociedade de classes. Rio de Janeiro: Zahar, 1968.

RIBEIRO, Darcy. O povo brasileiro: a formação e o sentido do Brasil. São Paulo: Companhia das Letras, 1997.

VARGA, István van Deursen. Dos medicamentos aos índios "genéricos": sobre os problemas e desafios legados, pelo governo Fernando Henrique Cardoso, aos campos das políticas indigenista e de saúde para os povos indígenas no Brasil (documento encaminhado ao governo Lula, como subsídio para aprofundar as discussões acerca da proposta resultante do seminário "Bases para uma nova política indigenista - 2", realizado pelo LACED/Museu Nacional, APOINME e COIAB). São Paulo, 2003. Mimeo.

. Pelas fronteiras e trincheiras do indigenismo e do sanitarismo: a atenção às DST em comunidades indígenas, no contexto das políticas e práticas indigenistas e de saúde, na Pré-Amazônia. 2002. Tese (Doutorado) - Faculdade de Saúde Pública, Universidade de São Paulo, 2002.

; GARCEZ, Jeovany. Censo da população indígena residente na Vila Santa Rosa, município de Amarante do Maranhão. Imperatriz: Projeto de atenção às DST para comunidades indígenas do Maranhão - UFMACCS/ MSA, Funai/AER-Imperatriz, 1998. Mimeo. 